\section{Liebe, Demut und Respekt}

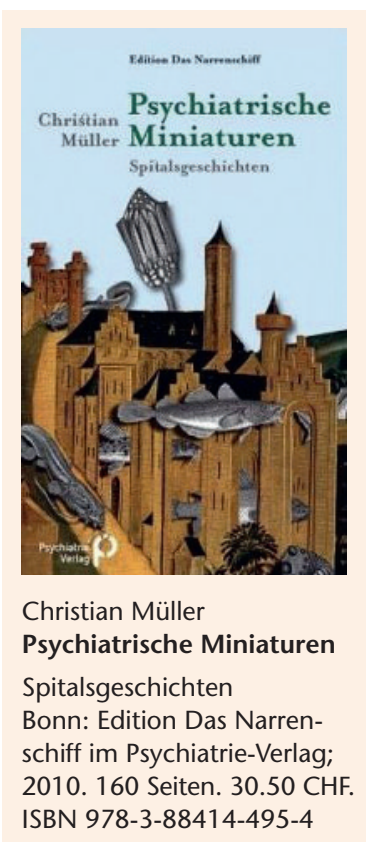

Ein Mensch, der sich mit Liebe, Demut und Respekt für seine Patienten einsetzt, dabei immer wieder zweifelt. Das ist der Eindruck, den die Lektüre dieses Büchleins hinterlässt. Christian Müller, ehemaliger Direktor einer grossen psychiatrischen Klinik bei Lausanne, erinnert sich: an seine Kindheit auf dem Gelände einer psychiatrischen Anstalt, die Assistentenzeit und vor allem an seine Zeit als Chefarzt. Der Alltag in der Klinik mit typischen und aussergewöhnlichen Vorkommnissen - aber auch Erlebnisse als Privatperson mit Kranken, «Auffälligen» und ihrem Umfeld - werden knapp und präzise geschildert und von eigenen Gedanken begleitet.

Der Leser wird Zeuge der grossen Veränderungen in den psychiatrischen Kliniken, des Wandels von der einstigen Anstalt zur modernen offenen Klinik, der für viele unbestrittene Vorteile hat - doch andere verunsichert, denen die vertraute Umgebung, ihr über Jahrzehnte gewohntes Zuhause entrissen wurde. Auch die Psychiatriereform in Italien, die der Autor auf Besuchen kennenlernt, hat ihre Schattenseiten. Die Ärzte sind ständig an Sitzungen und nicht bei ihren Patienten.

Was immer wieder beeindruckt: die Nähe des Direktors zu seinen Patienten und Mitarbeitern (er setzt sich in der Küche hin und schält mit ihnen Kartoffeln), gleichzeitig der Respekt, den er ihnen entgegenbringt, sein offenes Ohr für ihre grossen und kleinen Sorgen und Nöte, sein ruhiges Warten und Zuhören im Patientengespräch, auch wenn er «keine Zeit» hat, das Einbeziehen der Umgebung als wichtiges Element für Verständnis und Genesung der Pa- tienten - so gesundet ein verwirrter Süditaliener nach dem Verzehr von heimatlichem Brot, von der Mutter gebacken und vom Bruder in die Klinik gebracht.

Der Psychiater, gewohnt, den verborgenen Dingen im Leben nachzugehen, tief in die Seele seiner Patienten vorzudringen, steigt mit Seil und Laterne in die Tiefe eines alten Brunnens. Darf man das, fragt er sich, dem Erdschoss die tiefsten Geheimnisse entreissen? Auch hier: Respekt. Und immer wieder Zweifel, ob sein Handeln richtig ist. Er steigt auch in die Höhe, wenn es sein muss, um genug nahe bei seinen Patienten zu sein: Vor versammeltem Personal, Polizei und Feuerwehrleuten klettert er im weissen flatternden Arztmantel auf eine lange Leiter, um einen jungen Mann («Ich bin Christus. Geh weg von hier, Satan!») zu überreden, vom Baum zu steigen statt «davonzufliegen»: Amarcord - so die Überschrift dieses Kapitels. Auch hier wieder: Liebe zu seinen Patienten.

Das Buch beginnt mit Kindheitserinnerungen und schliesst mit dem pensionierten Chefarzt und alternden Mann. Nun ist Stille da, wie ein stetiges leises Regengeriesel. Bis er nur noch seinen Herzschlag hört, der ihm das Leben anzeigt, ihn aber auch daran erinnert, dass das Herz einmal ruhen wird, und erst dann die wahre, eigentliche Stille eintreten wird. «Wir sollten uns darauf vorbereiten», sagt der Autor zu einem Freund. Mit diesem Satz entlässt er den Leser in seine eigene Stille. Sie ist willkommen, um dieses wunderbare Büchlein nachklingen zu lassen.

Martin Sonderegger, Winterthur 